\title{
Correction to: Blockchain-assisted secured data management framework for health information analysis based on Internet of Medical Things
}

\author{
Asad Abbas $^{1} \cdot$ Roobaea Alroobaea $^{2} \cdot$ Moez Krichen $^{3,4} \cdot$ Saeed Rubaiee $^{5} \cdot$ S. Vimal $^{6} \cdot$ Fahad M. Almansour $^{7}$ \\ (C) Springer-Verlag London Ltd., part of Springer Nature 2021
}

Correction to: Personal and Ubiquitous Computing https://doi.org/10.1007/s00779-021-01583-8

The Fifth author's affiliation need to be changed in the published article.

Dr. S. Vimal

Department of Computer Science and Engineering

Ramco Institute of Technology

Rajapalayam

Tamilnadu

India

The original article has been corrected.

Publisher's note Springer Nature remains neutral with regard to jurisdictional claims in published maps and institutional affiliations.

The online version of the original article can be found at https://doi.org/ 10.1007/s00779-021-01583-8

Roobaea Alroobaea

r.robai@tu.edu.sa

Asad Abbas

asadabbas.grw@ucp.edu.pk

Moez Krichen

moez.krichen@redcad.org

Saeed Rubaiee

salrubaiee@uj.edu.sa

S. Vimal

svimalphd@gmail.com

Fahad M. Almansour

f.almansour@qu.edu.sa
1 Faculty of Information Technology, University of Central Punjab, Lahore, Pakistan

2 Department of Computer Science, College of Computers and Information Technology, Taif University, P. O. Box 11099 , Taif 21944, Saudi Arabia

3 Faculty of CSIT, Al-Baha University, Al Bahah, Saudi Arabia

4 ReDCAD Laboratory, University of Sfax, Sfax, Tunisia

5 Department of Mechanical and Materials Engineering, University of Jeddah, Jeddah, Saudi Arabia

6 Department of Computer Science and Engineering, Ramco Institute of Technology, Rajapalayam, Tamilnadu, India

7 Department of Computer Science, College of Sciences and Arts in Rass, Qassim University, Buraydah 51452, Saudi Arabia 